\title{
Peste des Petits Ruminants: Aetiology, Pathology, Immunology, Disease Status in Africa, Diagnosis, Control, Prevention and Treatment: A Review
}

\author{
Iniobong C.I. UGOCHUKWU ${ }^{1}$, Chukwunonso K. EZEASOR ${ }^{1}$, \\ Onyinyechukwu A. AGINA ${ }^{1 *}$, Davinson C. ANYOGU ${ }^{1}$, \\ Ijeoma C. CHUKWUDI ${ }^{2}$, Sunday I. IDOKO ${ }^{3}$, \\ Emmanuel I. UGOCHUKWU²
}

${ }^{1}$ University of Nigeria, Faculty of Veterinary Medicine, Department of Veterinary Pathology and Microbiology, Nsukka,Nigeria; onyinye.noel@unn.edu.ng (*corresponding author)

${ }^{2}$ University of Nigeria, Faculty of Veterinary Medicine, Department of Veterinary Medicine, Nsukka, Nigeria

${ }^{3}$ University of Abuja, Faculty of Veterinary Medicine, Department of Veterinary Pathology and Microbiology, Nigeria

\begin{abstract}
Peste des petits ruminants (PPR) is a disease of economic and veterinary importance leading to considerable economic losses. PPR affects small domestic and wild ruminants. Sheep and goats are the natural hosts of PPR but cattle, pigs, African buffaloes and camels are also affected by the PPR virus. Clinical signs seen are mainly fever, mucopurulent nasal and ocular discharges, cough, dyspnoea, gastroenteritis leading to severe diarrhoea. The post mortem lesions seen are congested lungs, congestion of gastrointestinal tract, especially the discontinuous streaks of congestion, which is referred to as Zebra stripes or Zebra markings, oedematous and congested retropharyngeal and mesenteric lymph nodes, linear haemorrhages in the intestinal mucosa and splenomegaly. PPR infection is characterized by a rise in packed cell volume (PCV), increase in haemoglobin concentration ( $\mathrm{HbC}$ ), leukopenia with lymphopenia. The serum alkaline phosphatase, alanine aminotransferase and aspartate aminotransferase activities are elevated, blood urea nitrogen and creatinine concentrations are also elevated. The disease is also characterized by disseminated intravascular coagulopathy (DIC) evidenced by prolonged prothrombin time (PT), prolonged activated thromboplastin time (APTT), thrombocytopenia, and hypofibrinogenemia. In PPR infection, serum biomarkers of oxidative stress such as vitamins A, C, E and glutathione activity decreases while serum catalase, superoxide dismutase, glutathione reductase and xanthine oxidase increase. Diagnostic techniques include histopathology, virus isolation, immunocapture enzyme-linked immunosorbent assay (icELISA), Competitive Enzyme Linked Imunnosorbent Assay (cELISA) and Combined Indirect ELISA (CI-ELISA) agar gel immunodiffusion, real-time polymerase chain reaction (RT-PCR), reverse transcription-loop mediated isothermal amplification assay (RT-LAMP), Luciferase immunoprecipitation system (LIPS) and immunohistochemistry. Therefore, this review focused on the aetiology, epidemiology, pathology, immunology, and disease status in Africa, diagnosis, control, prevention, treatment and control of this disease.
\end{abstract}

Keywords: Africa; disseminated intravascular coagulopathy; gastroenteritis; haemorrhages; hypofibrinogenemia; Peste des petits ruminants

\section{Introduction}

Peste des petits ruminants (PPR) is an acute, highly contagious and devastating disease of small ruminants which leads to high morbidity and case fatality thereby resulting in withering economic consequences to the livestock industry (Soltan and Abd-Eldaim, 2014; Kumar et al., 2017). This disease has devastating effects and produces significant socioeconomic impact (Torsson et al., 2016). These small ruminants play an important role in the food production chain of developing countries (Mbyuzi et al., 2014). Small ruminant production is an important economic enterprise in developing countries, especially in the humid tropics (Boyazoglu et al., 2005) and considering the importance of sheep and goats in the livelihood of the poor and marginal farmers in the African and Asian continents, PPR is therefore a critical concern for food 
security and poverty alleviation (Kumar et al., 2014). The affected sheep and goats are mostly owned by poor and vulnerable members of the human population of these areas (Muthuchelvan et al., 2014; Torsson et al., 2016). Peste des petits ruminants virus (PPRV) is the causative agent of this disease that affects small domestic and wild ruminants (Libeau et al., 2014; Torrson et al., 2016). It is prevalent in West Africa and the Middle East (Shaila et al., 1996). Sheep and goats are the natural hosts of PPR (Sevit and Sait, 2015). Cattle and pigs can also be infected with the virus, although they are not susceptible to clinical disease (Anderson and McKay, 1994; Sevit and Sait, 2015). African buffaloes and camels can also be infected (Albina $e t$ al., 2013). Due to its high mortality and morbidity rate, PPR is responsible for severe economic losses in the countries where it is endemic (Libeau et al., 2014).

\section{Aetiology}

The virus belongs to the genus Morbillivirus in the family Paramyxoviridae alongside measles virus, canine distemper virus, phocine distemper virus, cetacean morbillivirus, the newly discovered feline Morbillivirus and the recently eradicated rinderpest virus (Kumar et al., 2014; Torrson et al., 2016; Ugochukwu et al., 2018). In 1979, it was classified as the fourth member of the Morbillivirus genus (Buczkowski et al., 2014). The virus exists as single serotype, which is grouped into four distinct lineages (I, II, III, and IV) based on sequence comparison of small sequences of $\mathrm{F}$ gene (Shaila et al., 1996) or $\mathrm{N}$ gene (Kwiatek et al., 2007). All four lineages have been detected recently in Africa whilst only lineage IV is circulating across Asia (Banyard et al., 2010; Parida et al., 2015). Lineages I and II have been found exclusively in West Africa and lineage I has not been reported since 1994, whereas lineage II is circulating in Western and Central Africa (Libeau et al., 2014). Lineage III is restricted to East Africa and Middle East and southern India (Muthuchelvan et al., 2014). Lineage IV is found in Turkey the Middle East, South Asia and China (Dhar et al., 2002; Banyard et al., 2010; Kwiatek et al., 2011, Li et al., 2016).

\section{Epidemiology}

Peste des petits ruminants have been reported in SubSaharan Africa, North Africa, South and Central Asia, the Middle-East, Near East, and Far East Asia. (Dhar et al., 2002; Banyard et al., 2010; Albina et al., 2013; Libeau et al., 2014; Wang et al., 2015). The disease is currently circulating in Asian and African countries, creating enormous health problems in small ruminant populations (Sen et al., 2010). More than one billion sheep and goats worldwide are at risk (Albina et al., 2013). Sporadic outbreaks of PPR have been reported in both the Anatolia (Asian Turkey) and Thrace (European Turkey) parts of Turkey since it was first officially reported in 1999 (OIE, 1999; Ozkul et al., 2002; Albina et al., 2013; Sevik, 2014). Peste des petits ruminants virus is transmitted through inhalation and direct contact with ocular/nasal secretions, faeces, contaminated water and feeds (Saliki et al., 1993). Severity of the disease is more in goats than sheep
(Muthuchelvan et al., 2014) but this is not always the case; cattle and pigs can be infected sub-clinically by experimental infections (Taylor, 1984; Chowdhury et al., 2014).

\section{Pathology}

\section{Pathogenicity}

All viruses within the order Mononegavirales contain a negative-sense single-stranded RNA genome that consists of six open reading frames which encodes six structural and two non-structural proteins. The nucleocapsid (N), phosphoprotein $(\mathrm{P})$ and large polymerase protein $(\mathrm{L})$, in tandem with the viral RNA, form the ribonucleoprotein complex (RNP). The matrix (M) protein forms a link between the RNP and the host cell derived plasma membrane, covered evenly with distinctive spikes of the viral glycoproteins, the haemagglutinin $(\mathrm{H})$ and fusion proteins $(\mathrm{F})$. The interaction between the $\mathrm{H}$ and $\mathrm{F}$ proteins regulates the virus entry into a host cell (Buczkowski et al., 2014). In the pathogenicity of this virus, Lymph nodes, other lymphoid tissues and digestive tract organs were the predominant sites of virus replication (Troung et al., 2014).

\section{Clinicalsigns}

Morbidity and mortality rates can be as high as $80-100 \%$ in herds. Nonetheless, in endemic areas, morbidity and mortality range between 10 and $100 \%$ where previous immunity, age and species of infected animal define the severity of the resultant outcome (Torrson et al., 2016).

Clinical signs associated with PPR are severe pyrexia $\left(40-41{ }^{\circ} \mathrm{C}\right)$, followed by mucopurulent nasal and ocular discharges (Fig. 1), cough, dyspnoea, erosive and necrotic stomatitis (Fig. 2) with sores in the mouth, gastroenteritis, this ultimately leading to diarrhoea (Fig. 3), conjunctivitis, constipation. These painful sores in the oral mucous membranes prevent the animal from eating and, in synergy with the watery diarrhoea, leads to severe dehydration. This can result in the death of the animal within 10-12 days after the onset of pyrexia (Soltan and Abd-Eldaim, 2014; Sevit and Sait, 2015; Berguido et al., 2016; Torrson et al., 2016; Ugochukwu et al., 2017). There are also respiratory signs which include dyspnoea and coughing (AU-IBAR, 2014).

\section{Necropsy findings}

The pathology of PPR is characterized by retrogressive and necrotic changes in lymphoid tissues and epithelial cells of gastrointestinal and respiratory systems (Balamurugan $e t$ al., 2014). Gross necropsy findings include congested lungs (especially affecting the cranial lobes), congestion of gastrointestinal tract and nasal sinuses, oedematous, congested retropharyngeal and mesenteric lymph nodes, linear haemorrhages in the intestinal mucosa and splenomegaly (Kumar et al., 2004; Torrson et al., 2016). Clinical signs can be very similar to, and sometimes confused with other small ruminant diseases. Moreover, secondary bacterial infections can also escalate clinical signs, making PPR a disease difficult to diagnose under field conditions (Torrson et al., 2016).

Gross examination of respiratory tract reveals the following findings: frothy exudates and haemorrhages in 
14

tracheal mucosa, emphysema, varying degrees of congestion (Fig. 4), haemorrhages and red hepatization were observed in the lungs (Chowdhury et al., 2014; Ugochukwu et al., 2018). Whereas in the digestive tract specifically, in the intestines, there is hyperemia (Fig. 5) and haemorrhagic strips were found on mucosal surface of caecum, sometimes, with raised nodules (Chowdhury et al., 2014) but specifically, in the posterior part of colon and rectum, there were discontinuous streaks of congestion ("Zebra" stripes or "Zebra markings") on the mucosal folds as shown in Fig. 6 (Balamurugan et al., 2014; Ugochukwu et al., 2018). There are also erosions in the abomasum, duodenum, ileum and large intestines (AU-IBAR, 2014). Spleen shows characteristics lesions of splenomegaly and oedema (Patel et al., 2017). According to Chowdhury et al. (2014), the lymph nodes especially those of the mesentery will be severely oedematous, congested and enlarged. Additionally, in PPR cases, there could be haemorrhages on the surface of the liver, presence of serosengunious fluid in pericardial sac of heart and minor haemorrhages on cortico - medullary junction of kidney (Patel et al., 2017). Carcass of the animals that had PPR infection will shows signs of emaciation and soiled hindquarters with soft and watery faeces, eyes and nose containing crusty discharges, necrotic or orf-like lesions in the lips (Fig. 6) (Ugochukwu et al., 2017), gums, cheeks and ventral surface of tongue (AUIBAR, 2014).

\section{Histopathological findings}

Histopathological examination of lungs shows alveolar dilatation, emphysema, thickening of alveolar septa and infiltration of mononuclear cells (Fig. 8) (Ezeasor, 2012; Maina et al., 2015a; Patel et al., 2017), eosinophilic intracytoplasmic inclusion body and interstitial pneumonia evident with serous exudation. There are exudates in bronchioles, necrosis and sloughing of bronchial epithelium.

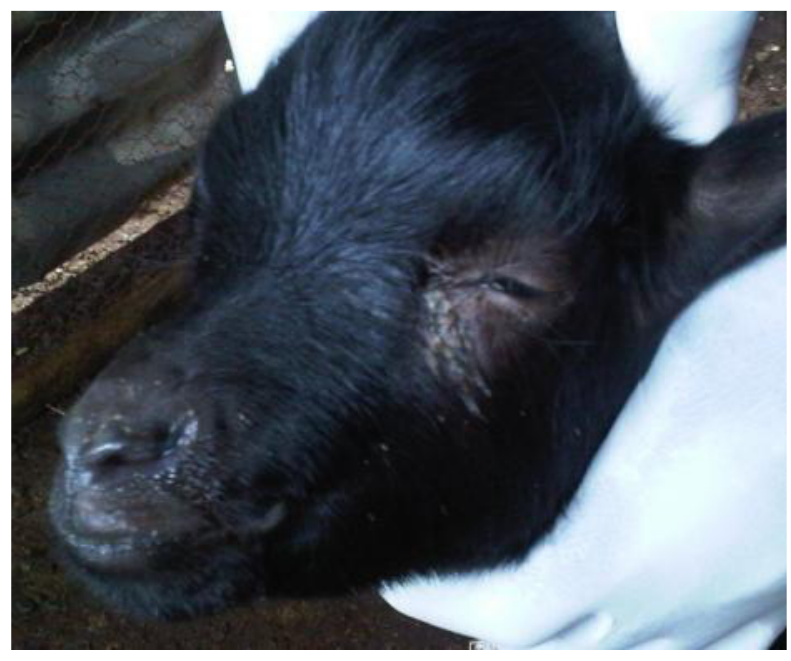

Fig. 1. Catarrhal nasal discharges
Syncytial cells and eosinophilic intracytoplasmic inclusion body is also a constant finding in bronchial epithelial cells (Kul et al., 2007; Saglam and Temur, 2009; Patel et al., 2017). In trachea, degeneration and cystic lesions in tracheal gland and infiltration of mononuclear inflammatory cells in tracheal sub-mucosa are observed. In intestine, atrophic villi with partial denudation of epithelial lining and intense diffusion of mononuclear cells in the lamina propria and sub-mucosa necrosis of epithelium/crypts, haemorrhages and infiltration of mononuclear cells into submucosa with sever loss of intestinal villi are common findings (Fig. 6) (Aktas et al., 2011; Chowdhury et al., 2014; Maina et al., 2015a, Patel et al., 2017). Loss of intestinal villi might be due to the epitheliotropic nature of PPR virus (Maina et al., 2015a). This may lead to necrosis of epithelial layer of villi (Patel et al., 2015). Spleen and lymph node will show haemorrhages and depletion of lymphoid cell in cortex and medullary cords (Fig. 9) (Maina et al., 2015b; Patel et al., 2017). Evident lymphoid cell depletion is observed in cortex and medullary cords of spleen and lymph node (Patel et al., 2017), and in the Peyer's patches (Fig. 10) (Ezeasor, 2012; Chowdhury et al., 2014). This depletion might be due to the severe lymphocytolysis in lymphoid tissues caused by the PPR virus (Kul et al., 2007).

In PPR infections, liver shows lesions of degeneration, sinusoidal congestion and infiltration of mononuclear cells in the inter-sinusoidal space (Patel et al., 2017). In the kidney, degenerative changes are accompanied by desquamation of epithelium lining of tubules, haemorrhages, mild glomerular atrophy and interstitial nephritis (Patel et al., 2017). While mild pathological changes are observed in the heart such as congestion, haemorrhages, degenerative changes, infiltration of mononuclear cells and focal area of necrosis (Jagtap et al., 2012; Patel et al., 2017).

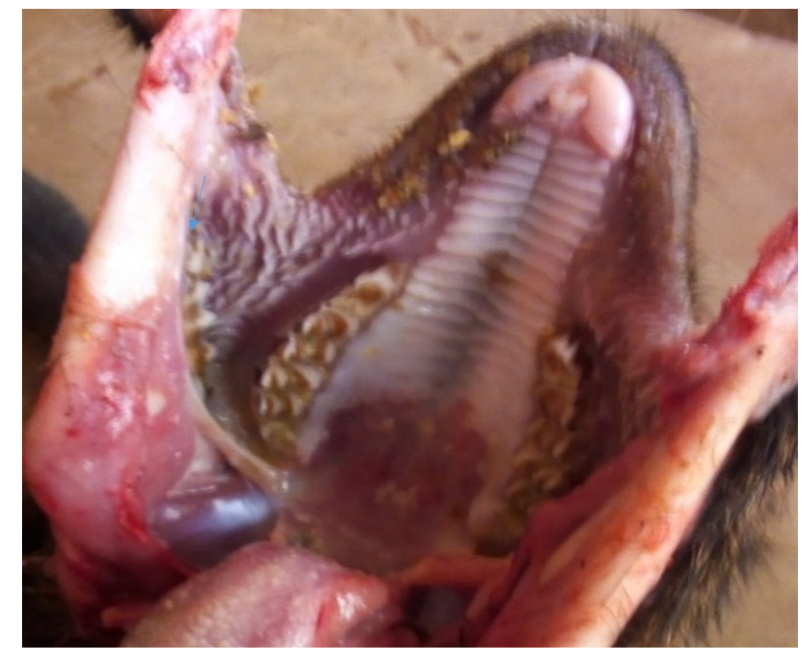

Fig. 2. The oral cavity from a field case of PPR showing severe mucosal ulceration on the soft palate (arrow) 


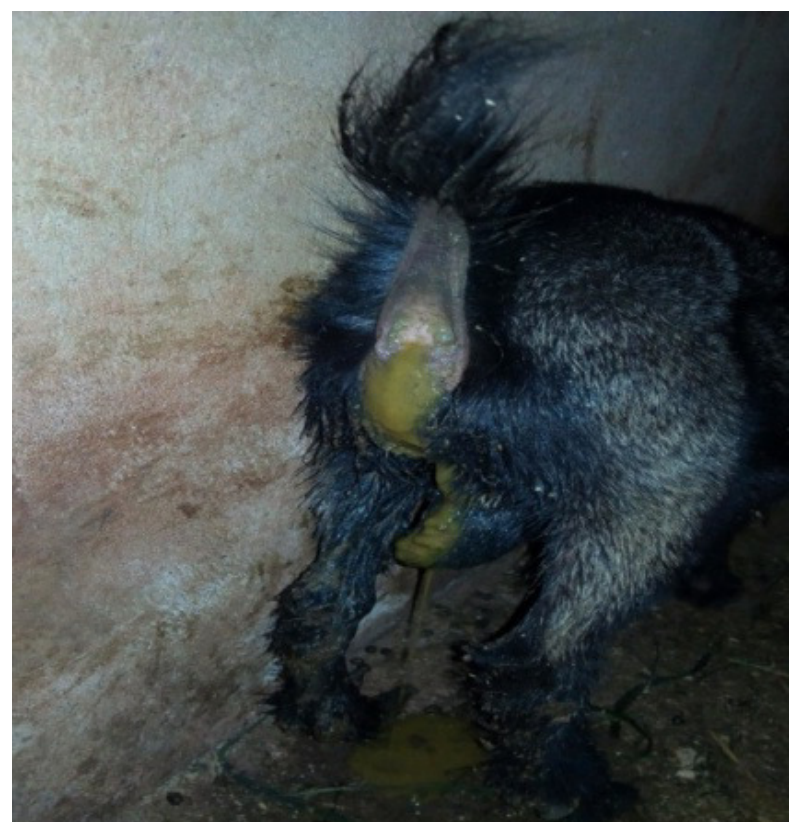

Fig. 3. Diarrhoea observed at the terminal stage of PPR

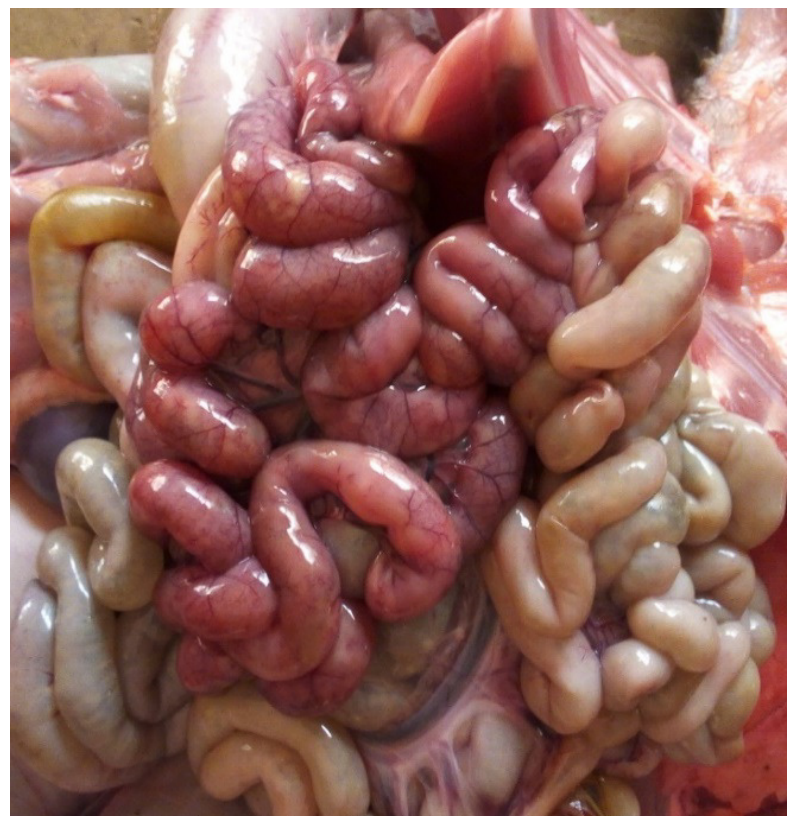

Fig. 5. The small intestines showing severe hyperemia of the serosal surfaces

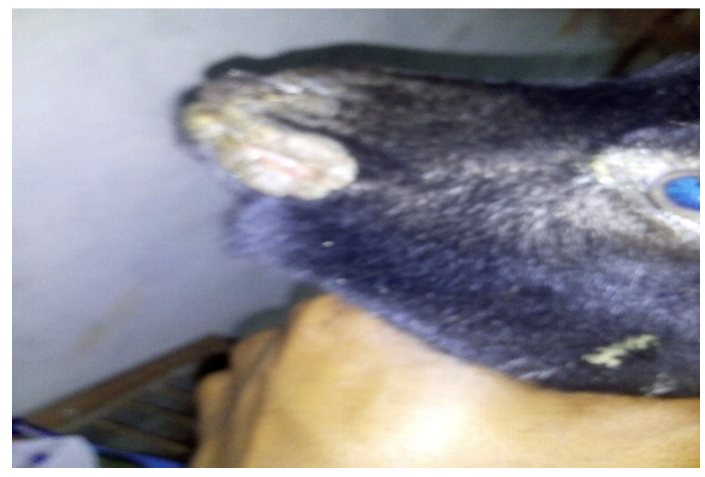

Fig. 7. Labial Orf-like lesions

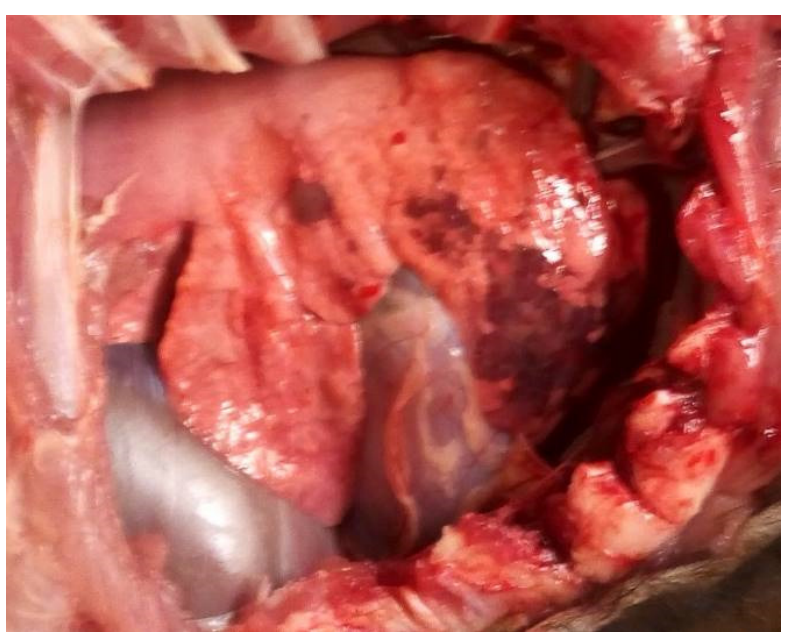

Fig. 4. The lungs showing patchy areas of lung consolidations in the cranial and middle lung lobes. This is consistent with super-infection with certain strains of Mannhiemia haemolytica or Pastueralla multocida

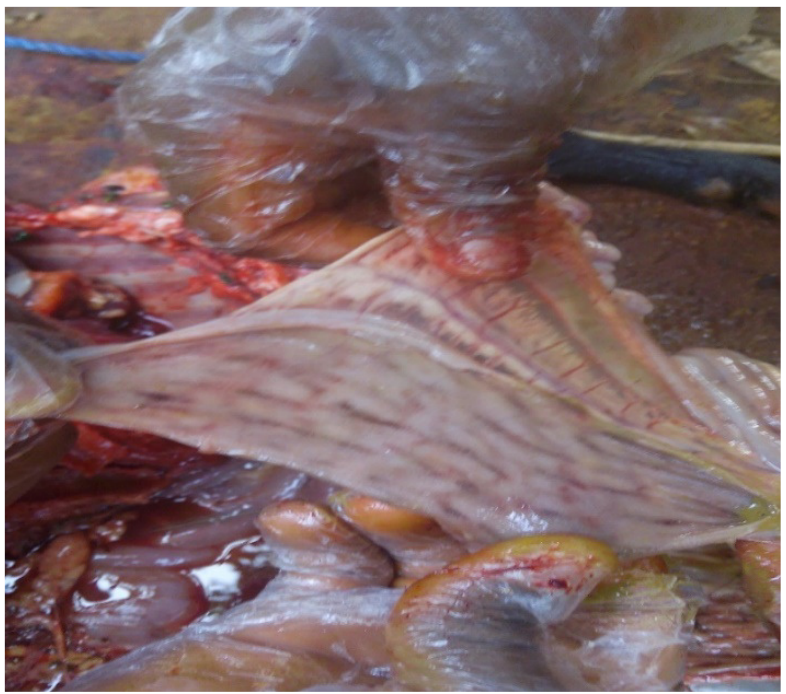

Fig. 6. Discontinuous streaks of congestion (Zebra-markings) in the mucosa of the colon and rectum

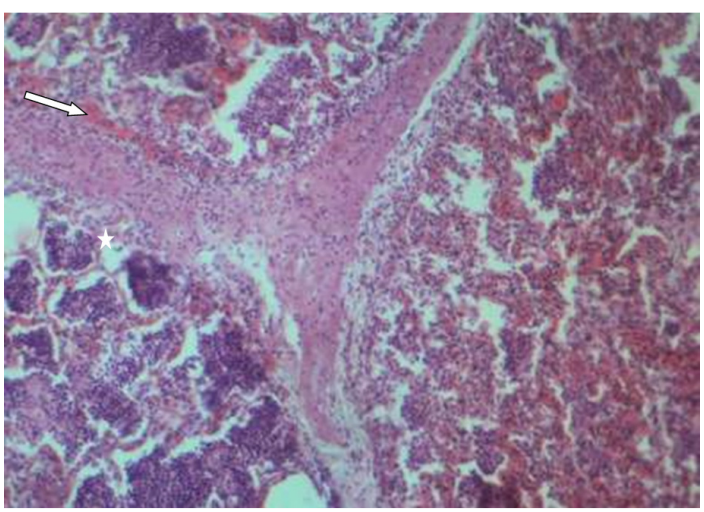

Fig. 8. Interlobular septae thickened by fibrin and cellular infiltrates (arrow). Also, notice the alveoli filled with cellular infiltrates (star). H\&E $\times 100$ (Ezeasor, 2012) 
16

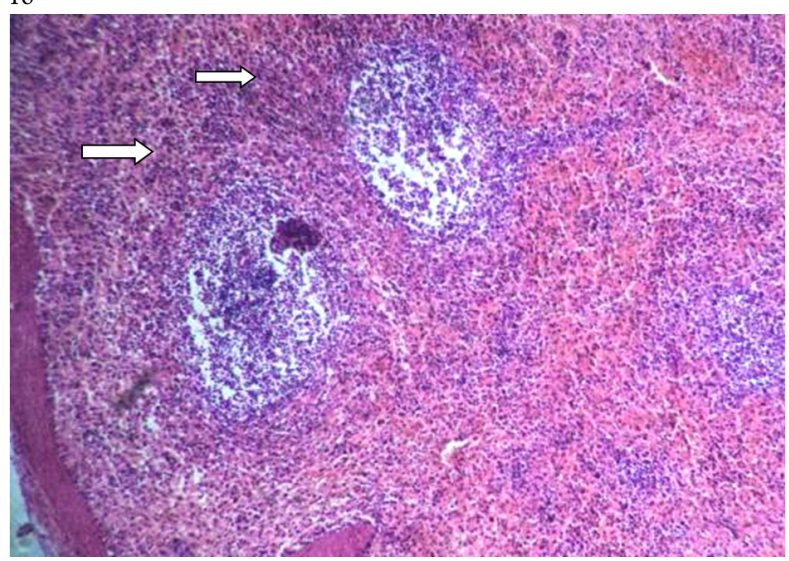

Fig. 9. Spleen: showing severe lymphoid depletion of the germinal centers. $\mathrm{H} \& \mathrm{E} \times 100($ Ezeasor, 2012)

\section{Immunohistochemical findings}

Specific immune-histochemical staining was characterized by a diffuse red granular reaction in the cytoplasm and nucleus. Specifically, the PPR virus antigens are localized in the cytoplasm and nuclei of alveolar and bronchiolar epithelia, alveolar macrophages, syncytial cells of the lungs, labial, intestinal, and bronchiolar epithelial cells, the lymphoid (intact and necrotic) and reticular cells in lymphoid organs (Kumar et al., 2004; Chowdhury et al., 2014).

\section{Haematology and serum biochemical findings}

Peste des petits ruminants infection in goats can lead to marked suppression of host immune response accompanied by severe leukopenia due to lymphopenia, which may increase the incidence and severity of other diseases (Rajak et al., 2005). PPR infection in goats is characterized by an increase in packed cell volume (PCV), an increase in the haemoglobin concentration ( $\mathrm{HbC})$, neutrophilia and lymphopenia (Aytekin et al., 2011; Das et al., 2015; Maina et al., 2015; Ugochukwu et al., 2018). A marked neutrophilia is usually due to combined effect of the virus and stress (Kataria and Kataria, 2004). These increases in erythrocytic parameters are probably due to haemoconcentration which develops because of diarrhoea in the later stages of PPR infection in small ruminants (Rossiter, 2004; Ugochukwu, 2011). The serum alkaline phosphatase, alanine aminotransferase and asparate aminotransferase are elevated (Sahinduran et al., 2012). Blood urea nitrogen and creatinine concentrations are also elevated (Sahinduran et al., 2012). The disease is also characterized by disseminated intravascular coagulopathy (DIC) evidenced by prolonged prothrombin time (PT), prolonged activated thromboplastin time (APTT), thrombocytopenia, and hypofibrinogenemia (Sahinduran et al., 2012). Serum biomarkers of oxidative stress such as vitamins $\mathrm{A}, \mathrm{C}, \mathrm{E}$ and glutathione activity decreases while serum catalase, superoxide dismutase, glutathione reductase and xanthine oxidase increase in PPR infection in sheep (Kataria and Kataria, 2012). Increased plasma malondialdehyde have also been reported in Black Bengal goats (Kumar et al., 2018)

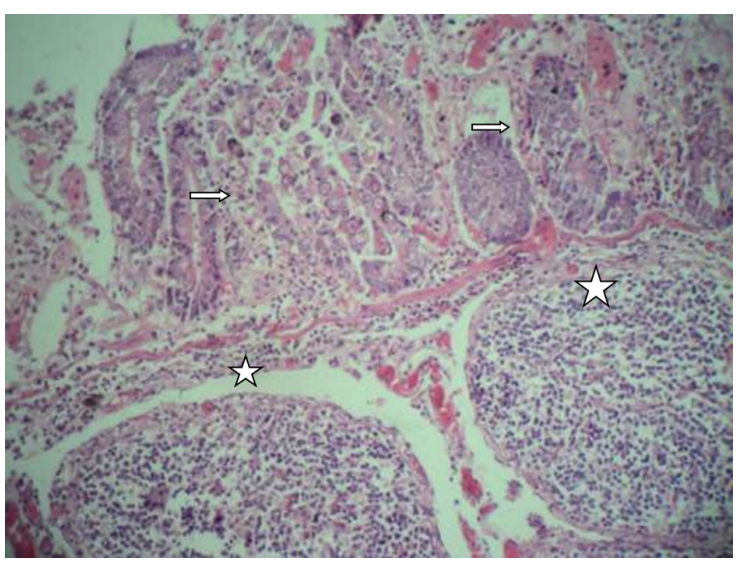

Fig. 10. Ileum, showing lymphoid depletion of the Payer's patches (star) and severe glandular epithelial cell necrosis (arrow) H\&E $\times 100$ (Ezeasor, 2012)

\section{Immunology}

Virus transmission occurs mainly by direct contact and the PPR virus does not survive for long outside the host. The infectious period is short, and animals do not become carriers, either dying or recovering with subsequent lifelong immunity (Mariner et al., 2016). PPRV is highly immunosuppressive, but the host immune responses against vaccine and infection can mount an effective immunity to PPRV mediated by both cellular and humoral immunity. The T-and B-cell epitopes have been identified against nucleocapsid and haemagglutination-neuraminidase proteins, which provide a foundation for understanding the nature of immunity against PPRV and for the development of assays for epidemiology and disease surveillance (Munir $e t$ al., 2013).

PPRV causes marked immunosuppression as evidenced by leukopenia, lymphopenia, and reduced early antibody response to both specific and nonspecific antigen. These observations are predominant particularly during acute phase of disease usually 4-10 days post-infection. On the other hand, the virus can induce only a transient lymphopenia without significantly affecting the immune response to nonspecific antigen or to itself during this postinfection period (Rajak et al., 2006). In morbilliviruses, the surface glycoproteins, $\mathrm{H}$ and $\mathrm{F}$ are highly immunogenic and confer protective immunity. PPRV is antigenically closely related to RPV and antibodies against PPRV are both crossneutralising and cross-protective (Taylor, 1979; Balamurugan et al., 2014). To eliminate the virus, it would be far more effective to identify the pockets of endemicity responsible for virus persistence and create high levels of vaccination immunity in these defined populations, as was done in the final stages of RP eradication (Mariner et al., 2016)

\section{Disease status in Africa}

PPR is endemic in most parts of Africa - East, Central and West Africa being the endemic foci with about $56 \%$ of countries in Africa affected by PPR. This disease is posing risk of spread towards South with case reports in Democratic Republic of Congo (DRC) in 2005, Tanzania 
in 2008 and Zambia in the year 2010 becoming the recently infected countries in the region. PPRV is endemic in East Africa. This is evidenced by the detection of antibodies to PPRV in Kenya in the years 1999 and 2009, Uganda (2005 and 2007). PPRV isolates belonging to lineage III have been characterized in Sudan (2000), Uganda (2007), and most recently in Tanzania in the years 2008 and 2010. Lineage IV PPRV have also been isolated from the Sudan in 2000, 2004, 2008 and 2009 (Banyard et al., 2010; Khalafalla et al., 2010).

PPR was officially confirmed in domestic animals in the Ngorongoro district of Tanzania in 2008 (reference). It is now considered to be endemic in the domestic sheep and goat populations throughout Tanzania, but restricted to one or more areas in the small ruminant wildlife population (Torrson et al., 2016). PPRV has been diagnosed in some countries of Central Africa. These include Central African Republic (CAR) in the years 1999, 2005 and 2006, Congo (2006), Chad (1999 and 2006), Cameroon (2009) (Awa et al., 2000) and Gabon (2007) (Banyard et al., 2010). Phylogenetic analysis has shown that lineage IV viruses are circulating across Central Africa. A first occurrence was reported in Cabinda, Angola in October 2012 (Banyard et al., 2010). An unexpected increase in morbidity and mortality of PPR was reported by DRC in January 2012 (Domenech, 2013)

Egyptian veterinary medical authorities stated that Egypt is free from PPRV, and Egypt was officially free of PPR according to the OIE until the outbreaks at sheep farms in Ismailia and Cairo provinces in 2012 (OIE, 2012) however, Soltan and Abd-Eldaim (2014), reported an emergence of peste des petits ruminants virus lineage IV in Ismailia Province, Egypt. PPR is believed to be endemic across much of West Africa. A number of West African countries have experienced significant outbreaks of PPRV. PPR cases has been reported severally in Nigeria even as recent as 2017 (Omeh et al., 2017, Ugochukwu et al., 2018).

PPR has also shown incursion to the Maghreb region Algeria being the most recently affected country in the region (2011) - Tunisia reported fresh outbreaks in 2010 (FAO/OIE, 2012) with reoccurring outbreaks in Libya (Ayari-Fakhfakh et al., 2011; Sghaier et al., 2014), Algeria (De Nardi et al., 2012; Kardjadj et al., 2015), Morocco (Muniraju et al., 2013; Fakri et al., 2016) Mauritania, and the Western Sahara (Baazizi et al., 2017). continuous circulation of the virus in the Maghreb region of North Africa and its recent move towards the Northern part of Algeria and Morocco approaching Gibraltar and the extensive trade links with Europe (Spain, France and Italy), this poses increased risk of introduction of PPR to Europe and it is a huge concern (Baazizi et al., 2017).

\section{Diagnosis}

Field diagnosis of PPR involves clinical diagnosis, however, post-mortem findings could aid in diagnosis (AUIBAR, 2014). There are also current methods for detecting PPRVs, including virus isolation, immune-chromatographic pen side test, immune-capture enzyme-linked immunosorbent assay (icELISA) and agar gel immunodiffusion, these are time-consuming. Several methods for detecting the genome with high sensitivity and specificity, such as RT-PCR, real-time RT-PCR and reverse transcription-loop mediated isothermal amplification assay (RT-LAMP), which has such an intrinsic potential for point of care diagnosis have been recently extensively used for laboratory diagnosis of PPRV infections (Bao et al., 2008; Batten et al., 2011; Couacy-Hymann et al., 2002; Li et al., 2010, 2016 Baron et al., 2016; Ashraf et al., 2017).

The following methods have been used with varying successes in the diagnosis of PPR; Luciferase Immunoprecipitation system (LIPS) (Berguido et al., 2016), competitive Enzyme Linked Imunnosorbent Assay (cELISA) and Combined Indirect ELISA (CI-ELISA) (Yousuf et al., 2015; Berguido et al., 2016; Ugochukwu et al., 2017). cELISA is based on serum antibody competition against a monoclonal anti-body targeting the nucleoprotein of PPRV (Libeau et al., 1995; Berguido et al., 2016). Virus isolation methods could also be used which involves observation of cytopathic effect on tissue cultures (lymph nodes, lungs, spleen, liver, whole blood and swabs) (Adombi et al., 2011; AU-IBAR, 2014).

\section{Differential diagnosis}

Historically, PPRV has often been confused with the closely related Rinderpest virus (Banyard et al., 2010) but due to the respiratory signs which characterize this disease, it could also be confused for contagious caprine pleuropneumonia (CCPP), pasteurellosis or Mannheimiosis. The last two can also be a secondary complication of Peste des petits ruminants. Bluetongue, contagious ecthyma, foot and mouth disease, mineral poisoning are also differential diagnosis due to the oral lesions they present which is similar to the one produced by PPR (Domenech, 2013).

\section{Control}

Control measures include strict quarantine and control of animal movements. Quarantine of newly purchased or newly arriving goats/sheep for at least 2-3 weeks to ascertain their health status and the source of any new animal(s) brought into the flock. Migratory flocks are threat to local sheep and goat therefore contact should be avoided (Balamurugan et al., 2014). Effective cleaning and disinfection of contaminated areas of all premises with disinfectants including fences, equipment and clothing is necessary. Dead animals/carcases should be burnt/ buried deeply. Monitor animals closely and frequently for any developing clinical signs of disease and isolate sick animals from the flock. Veterinarians should be contacted immediately to examine sick animals in the herd/flock. Administration of a live-attenuated vaccine should be done to confer strong immunity to the herd (Sen et al., 2010; Balamurugan et al., 2014). It is important to use separate facilities and staff to handle isolated animals, educate and train the employees about PPR and its clinical signs and the monitoring of wild and captive animals, especially those in contact with sheep and goats (Balamurugan et al., 2014).

Current control of the disease as earlier mentioned include administration of a live-attenuated vaccine, the maintenance of cold chain for vaccine efficacy has proven difficult especially in subtropical countries where power 
18

supply is not so regular (Sen et al., 2010). However, a thermostable live-attenuated conventional or recombinant vaccine is a way to avoid cold chain-associated problems in tropical and subtropical countries (Sen et al., 2010). The control of PPR in these regions could significantly contribute to poverty alleviation, therefore, the Office International des Epizooties (OIE) and Food and Agricultural Organization (FAO) have targeted the control and eradication of PPR by 2030 as a priority (Baazizi et al., 2017; Kumar et al., 2017), although the deadline for eradication was initially 2015 according to Ashraf et al. (2015). PPR can now be controlled by focused vaccinations in high-risk populations of sheep and goats, followed by mass vaccination campaigns. Mass vaccination of sheep and goats in endemic countries might be a pragmatic approach to control PPR and has been the main method of control (Sen et al., 2010; Sevik and Sait, 2015). These campaigns must achieve high levels of herd immunity (70\% to $80 \%)$ to block the epidemic cycle of the virus (Singh, 2011). Mass vaccination with vaccine based on lineage II PPRV Nigeria $75 / 1$ has being implemented routinely as a major control strategy in China (Wang et al., 2015). For countries considered as free from PPR, the best control measure will be test and slaughter of infected population to maintain the free status (Soltan and Abd- Eldaim, 2014).

\section{Prevention}

The impact of morbilliviruses on both human and animal populations is well documented in the history of mankind. Indeed, prior to the development of vaccines for these diseases, morbilliviruses plagued both humans and their livestock (Buczkowski et al., 2014). For many years the tissue culture rinderpest vaccine (TCRV) was used effectively to protect sheep and goats from PPRV with the cross-neutralising antibody response affording protection for at least 12 months (Buczkowski et al., 2014). However, the need to stop vaccinating animals with the TCRV during the rinderpest eradication meant that a homologous PPRV vaccine, Nigeria 75/1, was required (Buczkowski et al., 2014). This vaccine was generated by serial passages of a virulent PPRV strain in cell culture (Buczkowski et al., 2014) and was reported to be able to protect goats and sheep from challenge with wild-type PPRV isolates for at least 3 years post-vaccination (Saravanan et al., 2010; Buczkowski et al., 2014). The existence of only one serotype of PPRV means that this vaccine protects against challenge with viruses from all four PPRV lineages. Currently, several PPRV vaccines are licensed alongside the Nigeria 75/1 vaccine, with live attenuated Sungri/ 96, Arasur/ 87 and Coimbatore/ 97 vaccines being used in India (Saravanan $e t$ al., 2010).

\section{Treatment}

Since PPR is a viral disease, there is no specific treatment for this disease. Post-exposure therapeutic approaches for PPR infections are not mentioned much in the literature. However, treatment of affected animals by administration of antibiotics (long acting oxytetracycline, chlortetracycline) to prevent secondary bacterial infections and anti-diarrhoeal medicines has been practiced with supportive therapy (Bcomplex and Dextrose saline) for 5-7 days, which may be useful to reduce the severity of the disease. Treatment and management of clinical cases of PPR or in the event of outbreaks in sheep and goats is necessary in order to minimize the economic losses to farmers (Balamurugan et al., 2014; Ugochukwu et al., 2017).

\section{Conclusions}

Peste des Petits Ruminants is a devastating disease of small ruminants with its attendant enormous economic impact. This disease is endemic in Africa and Asia, and it is estimated that about 1 billion sheep and goats are at risk. It is important as one the most studied and researched virus of small ruminants, that we have a better understanding of the aetiology, lineages and transmission modes of this deadly virus. In addition to the aforementioned, this review helped throw light on the most recent information on the pathogenicity, macroscopic and microscopic pathology, haematological and serum biochemical findings associated with this disease, immunohistochemical findings, immunology, diagnosis, differential diagnosis, the prevention, treatment and control of this virus.

\section{References}

Aktas MS, Ozkanlar Y, Simsek N, Temur A, Kalkan Y (2011). Peste des petits ruminants in suckling lambs case report. Israel Journal of Veterinary Medicine 66(1):39-44.

Albina E, Kwiatek O, Minet C, Lancelot R, Servan de Almeida R, Libeau G (2013). Peste des petits ruminants, the next eradicated animal disease? Veterinary Microbiology 165(1-2):38-44.

Anderson J, McKay JA (1994). The detection of antibodies against peste des petits ruminants virus in cattle, sheep and goats and the possible implications to rinderpest control programmes. Epidemiology and Infection 112(1):225-231.

Ashraf W, Unger H, Haris S, Mobeen A, Farooq M, ... Khan QM (2017). Genetic detection of peste des petits ruminants virus under field conditions: a step forward towards disease eradication. BMC Veterinary Research 13(1):34.

Au-Ibar (2014). Standard methods and procedures (SMPs) for control of peste des petits ruminants (PPR) in the Greater Horn of Africa. Nairobi.

Aytekin I, Mamak N, Aykut U, Kalinbacak A (2011). Clinical, haematological, biochemical and pathological findings in lambs with peste des petits ruminants. Kafkas Universiti Veteriner Fakultesi Dergesi 17(3):349-355.

Baazizi R, Mahapatra M,Clarke RD, Ait-Oudhia K, Khelef D, Parida S (2017). Peste des petits ruminants (PPR): A neglected tropical disease in Maghreb region of North Africa and its threat to Europe. Plos One 12(4):e0175461.

Balamurugan V, Hemadri D, Gajendragad MR, Singh RK, Rahman H (2014). Diagnosis and control of peste des petits ruminants: a comprehensive review. Virus Disease 25(1):39-56.

Banyard AC, Parida S, Batten C, Oura C, Kwiatek O, Libeau G (2010). Global distribution of peste des petits ruminants virus and prospects for 
improved diagnosis and control. Journal of General Virology 91(12):2885-2897

Bao J, Li L, Wang Z, Barrett T, Suo L, ... Li J (2008). Development of onestep real-time RT-PCR assay for detection and quantitation of peste des petits ruminants virus. Journal of Virological Methods 148(1-2):232236.

Baron J, Fishbourne E, Couacy-Hyman E, Abubakar M, Jones BA, ... Baron MD (2014). Development and testing of a field diagnostic assay for peste des petits ruminants virus. Transbound Emerging Disease 61(5):390-396.

Batten CA, Banyard AC, KingDP, Henstock MR, Edwards L, ... Barrett T (2011). A real time RT-PCR assay for the specific detection of peste des petits ruminants virus. Journal of Virological Methods 171(2):401-404.

Berguido FJ, Sanne Charles Bodjo SC, Loitsch A, Diallo A (2016). Specific detection of peste des petits ruminants virus antibodies in sheep and goat sera by the luciferase immunoprecipitation system. Journal of Virological Methods 227:40-46.

Boyazoglu J, Hatziminaoglou I, Morand-Fehr P (2005). The role of the goat in society: past, present and perspectives for the future. Small Ruminant Research 60(1-2):13-23.

Buczkowski H, Muniraju M, Parida S, Banyard AC (2014). Morbillivirus vaccines: Recent successes and future hopes. Vaccine 32(26):3155-3161.

Chowdhury EH, Bhuiyan AR, Rahman MM, Siddique MSA, Islam MR (2014). Natural peste des petits ruminants virus infection in Black Bengal goats: virological, pathological and immunohistochemical investigation. BMC Veterinary Research 10(1):263.

Couacy-Hymann E, Roger F, Hurard C, Guillou JP, Libeau G, Diallo A (2002). Rapid and sensitive detection of peste des petits ruminants virus by apolymerase chain reaction assay. Journal of Virological Methods 100(1-2):17-25.

Das S, Nath R, Balamurugan V, Choudhury R, Devi M (2015). Haematobiochemical analysis of goats naturally infected with peste des petits ruminants. International Journal of Research in Emerging Science and Technology 2(9):19-24.

Dhar P, Sreenivasa BP, Barrett T, Corteyn M, Singh RP, Bandyopadhyay SK (2002). Recent epidemiology of peste des petits ruminants virus (PPRV). Veterinary Microbiology 88(2):153-159.

Domenech J (2013). Peste des petits ruminants (PPR) situation worldwide. Workshop on PPR prevention and control in the SADC Region 10-12 June2013, Dares Salam, Tanzania.

Ezeasor CK (2012). Evaluation of the protective effects of different routes of administration of Peste des Petits ruminants vaccine against Peste des Petits ruminants virus induced caprine pneumonia. Unpublished Masters dissertation, University of Ibadan, Oyo State, Nigeria.

FAO/OIE (2012). PPR situation in Africa. $7^{\text {th }}$ meeting of the GF-TADs steering committee for Africa (SC7) $16^{\text {th }}-17^{\text {h }}$ July, 2012.

Jagtap SP, Rajak KK, Garg UK, Sen A, Bhanuprakash V, ... Vanamayya PR (2012).Effect of immunosuppression on pathogenesis of peste des petits ruminants (PPR) virus infection in goats. Microbial Pathogenesis 52(4):217-226.

Kataria AK, Kataria N (2012). Evaluation of oxidative stress in sheep affected with peste des ruminants. Journal of Stress Physiology and Biochemistry $8(4): 72-77$.
Khalafalla AI, Saeed IK, Ali YH, Abdurrahman MB, Kwiatek O,... Abbas Z (2010). An outbreak of peste des petits ruminants (PPR) in camels in theSudan. Acta Tropica 116(2):161-165.

Kul O, Kabakci N, Atmaca HT, Ozkul A (2007). Natural peste des petits ruminants virus infection: novel pathologic findings resembling other morbillivirus infections. Veterinary Pathology 44(4):479-486.

Kumar N,Barua S, Riyesh T, Tripathi BN (2017) Advances in peste des petits ruminants vaccines. Veterinary Microbiology 206:91-101.

Kumar N,Maherchandani S, Kashyap SK, Singh SV,Sharma S, ... Ly H (2014) Peste des petits ruminants virus infection of small ruminants: a comprehensive review. Viruses 6(6):2287-327.

Kumar P, Tripathi BN, Sharma AK, Kumar R, Sreenivasa BP, ... Bandyopadhyay SK (2004). Pathological and immunohistochemical study of experimental peste des petits ruminants virus infection in goats. Journal of Veterinary Medicine, Series B 51(4):153-159.

Kumar P, Dey A, Kumar A, Ray PK, Chandran PC, ... Kumar M(2018). The effects of PPR on the reproductive health of Black Bengal goats and the possible role played by oxidative stress. Tropical Animal Health and Production 50(7):1441-1447.

Kwiatek O, Ali YH, Saeed IK, Khalafalla AI, Mohamed OI, ... Libeau G (2011). Asian lineage of peste des petits ruminants virus, Africa. EmergingInfectious Diseases 17(7):1223-1231.

Kwiatek O, Minet C, Grillet C, Hurard C, Carlsson E, ... Libeau G (2007). Peste des petits ruminants (PPR) outbreak in Tajikistan. Journal of Comparative Pathology 136(2-3):111-119.

Li L, Bao J, Wu X, WangZ, Wang J, ... LiJ (2010). Rapid detection of peste des petits ruminants virus by a reverse transcription loop-mediated isothermal amplification assay. Journal of Virological Methods 170(12):37-41.

Libeau G, Diallo A, Parida S (2014). Evolutionary genetics underlying the spread of peste des petits ruminants virus. Animal Front 4(1):1420.

Libeau G, Prehaud C, Lancelot R, Colas F, Guerre L, ... Diallo A (1995). Development of a competitive ELISA for detecting antibodies to thepeste des petits ruminants virus using a recombinant nucleoprotein. Research in Veterinary Science 58(1):50-55.

Lin Li, Xiaodong Wu, Fuxiao Liu, Zhiliang Wang, Chunju Liu, ... Jingyue Bao (2016). Rapid detection of lineage IV peste des petits ruminants virus by real-time RT-PCR Journal of Virological Methods 235:131133.

Maina SM, Gitao CG, Gathumbi PK (2015). Hematological, serological and virological findings in sheep and goats experimentally infected with lineage III peste des petits ruminants virus isolates in Kenya. Journal of Experimental Biology3(1):81-88.

Maina SM, Gitao CG, Gathumbi PK (2015). Clinico-pathological observations in sheep and goats exposed to lineage I peste des petits ruminants virus infection in Kenya. Journal of Experimental Biology and Agricultural Sciences 3(1):72-80.

Mariner JC, Jones BA, Rich KM, Thevasagayam S, Anderson J, ... Roeder PL (2016) The opportunity to eradicate peste des petits ruminants. Journal of Immunology 196(9):3499-3506.

Mbyuzi AO, Komba EVG, Kimera SI, Kambarage DM (2014). Seroprevalence and associated risk factors of peste des petits ruminants and contagious caprine pleuro-pneumonia in goats and sheep in the 
20

Southern Zone of Tanzania. Preventive Veterinary Medicine 116(12):138-144.

Munir M, Zohari S, Berg M (2013). Immunology and immunopathogenesis of peste des petits ruminants virus. In: Molecular biology and pathogenesis of peste des petits ruminants virus. Springer Briefs in Animal Sciences. Springer, Berlin, Heidelberg, pp 49-68.

Muthuchelvan D, Ankan DE, Bikas D, Dheeraj C, Gnanavel V, ... Satya P (2014). Molecular characterization of peste-des-petits ruminants virus (PPRV) isolated from an outbreak in the Indo-Bangladesh border of Tripura state of North-East India. Veterinary Microbiology 174(34):591-595.

OIE (Office International des Epizooties) (1999). OIE disease information, pp 137.

OIE (Office International des Epizooties) (2013). Peste des petits ruminants. Manual of diagnostic tests and vaccines for terrestrial animals. Chapter 2.7.11. Available at: ttp:// www. oie.int/ fileadmin /Home /eng/Health_standards/tahm/2.07.11_PPRpdf. hAccessed on 15 March 2018.

Omeh CN, Ugochukwu ICI, Ugochukwu EI (2017). Physiohaematological observations in West African dwarf goats with natural infection of peste des petits ruminants (PPR) Int. Journal of Biological Science and Technology 9(2):8-17.

Ozkul A, Akca Y, Alkan F, Barrett T, Karaoglu T, ... Burgu I (2002). Prevalence, distribution, and host range of peste des petits ruminants virus, Turkey. EmergingInfectious Diseases 8(7):708-712.

Parida S, Muniraju M, Mahapatra M, Muthuchelvan D, Buczkowski $H$, Banyard AC (2015).Peste des petits ruminants. Veterinary Microbiology 181(1-2):90-106.

Patel YR, Patel JM, Vihol PD, Kalyani IH, Solanki JB, Panchal PP (2017) Pathomorphological studies of peste des petits ruminants (ppr) in goats of Navsari and Valsad Districts, India. International Journal of Current Microbiology and Applied Science 6(12):238-244.

Rajak KK, Sreenivasa BP, Hosamani M, Singh RP, Singh RK, Bandyopadhyay SK (2006) Experimental studies on immunosuppressive effects of peste des petits ruminants (PPR) virus in goats. Comparative Immunology, Microbiology and Infectious Diseases 28(4):287-296.

Rossiter PB (2004). Peste des petits ruminants. In: Coetzer JAW, Tustin RC (eds) Infectious diseases of livestock. Oxford University Press, Volume 2. Cape Town, Southern-Africa, pp 660-672.

Saglam YS, Temur A (2009). Immunohistochemical detection of peste des petits ruminants (PPR) viral antigen from the cases of naturally occurring pneumonia in sheep. Kafkas Universitesi Veteriner Fakultesi Dergesi 15(3):423-428.

Sahinduran S, Albay MK, Sezer K, Ozmen O, Mamak N, ... Yildiz R (2011). Coagulation profile, haematological and biochemical changes in kids naturally infected with peste des petits ruminants. Tropical Animal Health and Production 44(3):453-457.

Saliki JT, Libeau G, House JA, Mebuus CA, Dubovi EJ (1993). Monoclonal antibody based blockingELISA for specific detection andtitration of PPR virus antibody in caprine and ovine sera. Journal of Clinical Microbiology 31(5):1075-1082.
Saravanan P, Sen A, Balamurugan V, Rajak KK, Bhanuprakash V, Palaniswami KS, Singh RK (2010). Comparative efficacy of peste des petits ruminants (PPR) vaccines. Biologicals 38(4):479-485.

Sen A, Saravanan P, Balamurugan V, Rajak KK, Sudhakar SB, ... Singh RK (2010). Vaccines against peste des petits ruminants virus. Expert Review of Vaccines 9(7):785-96.

Şevik M, Sait A (2015) Genetic characterization of peste des petits ruminants virus, Turkey 2009-2013. Research in Veterinary Science 101:187-195.

Shaila MS, Shamaki D, Forsyth MA, Diallo A, Goatley L, ... Barrett T (1996). Geographic distribution and epidemiology of peste des petits ruminantsvirus. Virus Research 43(2):149-153.

Singh RP (2011). Control strategies for peste des petits ruminants in small ruminants of India. Revue Scientifique et Technique-OIE 30(3):879887.

Soltan MA, Abd-Eldaim MM (2014). Emergence of peste des petits ruminants virus lineage IV in Ismailia Province, Egypt. Infection, Genetics andEvolution 28:4447.

Taylor WP (1979). Serological studies with the virus of peste des petits ruminants in Nigeria. Research in Veterinary Science 26(2):236-242.

Torsson E, Kgotlele T, Berg M, Mtui-Malamsha N, SwaiES, ... Misinzo G (2016). History and current status of peste des petits ruminants virus in Tanzania. Infection Ecology andEpidemiology 6(1):32701.

Truong T,Boshra H,Embury-Hyatt C,Nfon C,Gerdts V, ... Babiuk S (2014). Peste des petits ruminants virus tissue tropism and pathogenesis in sheep and goats following experimental infection. 559(1):e87145.

Ugochukwu EI (2011) Textbook of equine, porcine and ruminant medicine 1st edition. Computer Edge Publishers, Enugu.

Ugochukwu ICI, Ugochukwu EI, Chukwu CC (2017). Therapeutic response of West African dwarf goats infected with peste des petits ruminants whose oral lesions were treated with oxytetracycline long acting and gentian violet topical spray. Asian Pacific Journal of Tropical Disease 7(12):771-774.

Ugochukwu ICI, Ugochukwu EI, Chukwu CC (2018). Haematological parameters and serum biochemical assay of West African dwarf goats infected with peste des petits ruminants virus in Nsukka, Enugu State. Comparative Clinical Pathology27(1):13-19.

WangJ, Wang M, WangS, Liu Z, Shen N, ... Cai X(2015). Peste des petits ruminants virus in Heilongjiang province, China, 2014. Emerging Infectious Disease 21(4):677-680.

Wolhsein P, Saliki J (2006). Rinderpest and peste des petits ruminants - the diseases: clinical signs and pathology. In: Barrett T, Pastoret PP, Taylor, WP (Eds). Rinderpest and peste des petits ruminants: virus plagues of large and small ruminants. Elsevier, pp 68-85.

YousufRW, Sen A, Mondal B, Biswas SK, Chand K, ... Muthuchelvan D (2015). Development of a single-plate combined indirect ELISA (CIELISA) for the detection of antibodies against peste-des-petitsruminants and bluetongue viruses in goats. Small Ruminant Research 124:137-139. 